\title{
Proposition of an M-Business Procedure Model for the Development of Mobile User Interfaces
}

\author{
Susanne Glissmann ${ }^{1}$, Stefan Smolnik ${ }^{2}$, \\ Ragnar Schierholz ${ }^{1}$, Lutz Kolbe ${ }^{1}$, Walter Brenner ${ }^{1}$ \\ ${ }^{1}$ Institute of Information Management, University of St.Gallen, Switzerland, \\ ${ }^{1}$ \{susanne.glissmann | ragnar.schierholz | lutz.kolbe | walter.brenner\}@unisg.ch, \\ ${ }^{2}$ Department of Information Systems 2, European Business School, Germany, ${ }^{2}$ \\ Stefan.Smolnik@ebs.edu
}

\begin{abstract}
In the design of desktop applications, developers successfully deploy structured software life cycle models to simplify the development process. Applying these models in m-business often does not result in usable software. M-business applications differ from desktop applications mainly in their limited user interface as well as the new mobile and dynamic application context. Traditional software life cycle models do not consider these characteristics. Although, current mobile literature describes how m-business applications must be developed, they do not give structured guidelines for the development process of mobile user interfaces.

In this paper we propose an m-business procedure model for the development of mobile user interfaces. The model is based on established software engineering and human computer interaction design principles. It is concretized with detailed development recommendations regarding mobile issues and usability goals. An in-depth case study at a US software development company builds the basis for validation of the model's practicability.
\end{abstract}

\section{Introduction}

\subsection{Motivation}

The rising interest for mobile business (mbusiness), followed by the increasing demand for mobile applications has led to a high number of mobile application developments in recent years ([1]; [2]). But the development of usable m-business applications turned out to be difficult [3].

Although, mobile research has gained importance, it is still an evolving discipline. Commonly accepted prescriptions for the design of m-business applications have not yet been established [4]. In particular the design of mobile user interfaces (UI) is complex. The mobile device varies from the traditional personal computer (PC): its screen size, processor power and memory space are limited [5]. Keypad or pen to enter data are difficult to use and Internet access is often unstable ([6]; [5]). Furthermore, the context, in which the UI is applied, is characterized by its dynamic and complexity ([1]; [7]; [8]).

These changed UI requirements as well as yet limited insights in the field of m-business application design result in uncertainties regarding m-business application projects and lead to wrong decision-making. Often, projects take longer and are more expensive than planned [9], users do not accept the application because of low usability [10] and the rollout of the developed mobile application does not result in the expected success [3].

The introduction of structured guidelines similar to desktop software development procedure models, but adjusted to m-business characteristics aims to address the described problems and challenges. In particular a strong focus on the UI design will help to manage the design process' complexity and will increase the mbusiness application's user acceptability.

\subsection{Objective}

Objective of this paper is to propose structured design guidelines for the development process of $\mathrm{m}$ business applications. The design guidelines focus on the specific case of m-business applications, which are created by the enhancement of existing e-business applications by adding a new mobile user interface. For this, we developed an m-business procedure model. It is based on established software development as well as general and specific m-business human computer interaction (HCI) design principles. The development of the application's mobile UI takes center stage of the model.

The paper attempts to give answers to the following research questions: 
- Which stages must be passed in the development process of an m-business user interface?

- Which are the activities, results and challenges in each stage?

\subsection{Research Approach \& Structure}

As the research goal is the construction of a new model, we follow the approach of design science as described in [11]. Design science "seeks to create innovations that define the ideas, practices, technical capabilities, and products through which the analysis, design, implementation, management, and use of information system can be effectively and efficiently accomplished" [11]. It is composed of two activities: creating and evaluating an artifact. Artifacts cover constructs, models, methods, and instantiations. They can be evaluated through observational, analytical, experimental, testing as well as descriptive evaluation methods [11]. In this paper, we propose a model as artifact and evaluate this model with an observational evaluation method.

First, the subsequent section 2 describes the underlying theory of the m-business procedure model. In section 3 , the requirements for the model, an overview and the concrete stages of the m-business procedure model are explained. Activities, results and challenges, which are specific for the m-business UI, are emphasized. Common issues that are equal for the design of desktop as well as m-business applications are not further addressed. Following, in section 4 an evaluation of the model is given. The final section 5 summarizes the results and gives suggestions for further research.

\section{Background}

\subsection{Software Development Life Cycle Models}

For the design process of desktop applications software development procedure models, also called software development life cycle (SDLC) models, exist. Examples are the classical software life cycle, waterfall model, the rapid application development model (RAD), and the spiral model ([12], pp. 52-77; [13], pp. 79-138). These conceptual models are used in project management and describe the stages of an information system development project. They differ e.g. in the number of stages, level of detail or type of flow (cyclic versus sequential) ([13], p. 98). In general, these models consist of the stages: problem analysis, software design, implementation, integration and test, as well as maintenance [14].

\subsection{Human Computer Interaction Design Prin- ciples}

With growing number of different system users, the development of user interfaces evolved and became increasingly complex in the last two decades ([15]; [16], pp. xvii-xix). Hence, the user interface design has gained importance and HCI design principles were developed. For example, usability goals are applied to control and define the usability of a UI during and after the development process ([17], pp. 24-36). In order to increase the usability, e.g. task analysis ([18], pp. 51-126), use case modeling ([19], pp. 1-35) and general usability heuristics ([17], pp. 115-163), are established techniques. For the composition of desktop screen elements specific HCI guidelines are applied (e.g. [20]).

\subsection{User-centered Design Processes}

In addition to the advancements in SDLC models and HCI design principles, specific user-centered design processes exist. User- centered design processes resemble SDLC models. Differences are discernible in the strong focus of the user interface and the user being the focal point of the entire design process ([21], pp. 192-196). Established examples are the simple life cycle model for interaction, ISO 13407, usability engineering lifecycle, task centered system design ([22], pp. 192-196; [23]). User- centered design processes are generic and largely applied for the design of desktop applications. However, common user- centered design processes cannot be applied for mobile design. Design processes taking into consideration the anomaly of mbusiness UIs have not been established ([5]; [3]; [24], p.3).

The m-business procedure model has been developed according to Preece's simple life cycle of interaction ([22], pp. 201-277). Preece's model is built of four interrelated phases. It incorporates iteration and encourages a user focus. Nevertheless, to put the model into practice in a real project, further concretion is necessary ([22], p.183).

\section{A Procedure Model for M-Business Ap- plications}

\subsection{Requirements for the Model}

A model, which gives structured design guidelines for an m-business design process, must meet the following requirements. 
It has to be built of several stages representing the design process. The stages should define which activities must be conducted and which methods should be applied in each stage. Furthermore, it must specify the results for each stage. Additionally, by providing the model's challenges the software developer should become sensitive to difficult design issues. The course of action must be unambiguous between and within the stages.

To be able to support m-business projects, the model must consider mobile design issues. In particular, the strong focus on user-centered design is decisive for the final usability of the application.

Aim of the model is the management and the facilitation of m-business design processes. Therefore, a major requirement is the direct applicability of the model.

\subsection{Overview of the Model}

The m-business procedure model is a proposal for structured guidelines throughout the entire development process of m-business applications. The model is created for e-business applications, which will be enhanced through mobile UIs. The emphasis of the model is placed on the design of the application's mobile UI.

The model is composed of five sequential stages (see figure 1) in part derived from Preece's simple life cycle model for interaction ([21], pp. 201-277). For the development of the model, we focused on the aspects that differ notably from e-business projects in the following stages: (1) identify needs, (2) establish requirements, (3) conceptual design, (4) physical design, and (5) implementation. The stages were analyzed, adjusted and concretized regarding mobile design issues. The activities, challenges and results of each stage are further explained in the following section.

As mentioned before, the activity flow of software development models is either allowing regresses (cyclic) or requires solely progression (sequential). However, in the development process of mobile UIs, the process cannot entirely be defined to one type of flow. It is reasonable to allow regresses to only certain parts of the process. From stage 1 to 3 regressions are possible. Nevertheless, at the end of stage 3, conceptual design, the mobile device must be selected. After having initialized stage 4, physical design, it should not be returned to previous stages. Reason for this is that a different device type requires other physical design decisions. For example, the screen of a cell phone cannot show the same amount of data as a PDA screen. Therefore, changing the device at this stage would decrease the UI in its usability. Similar constraints ap- ply for the return from stage 5 to stage 4 . Nevertheless, in exceptional cases, e.g. the detection of wrong decisions made in a previous stage, regresses must be allowed. The stages, in which the wrong decision was reached, must be found and the mistake must be corrected. The subsequent stages have to be repeated according to the changed stage.

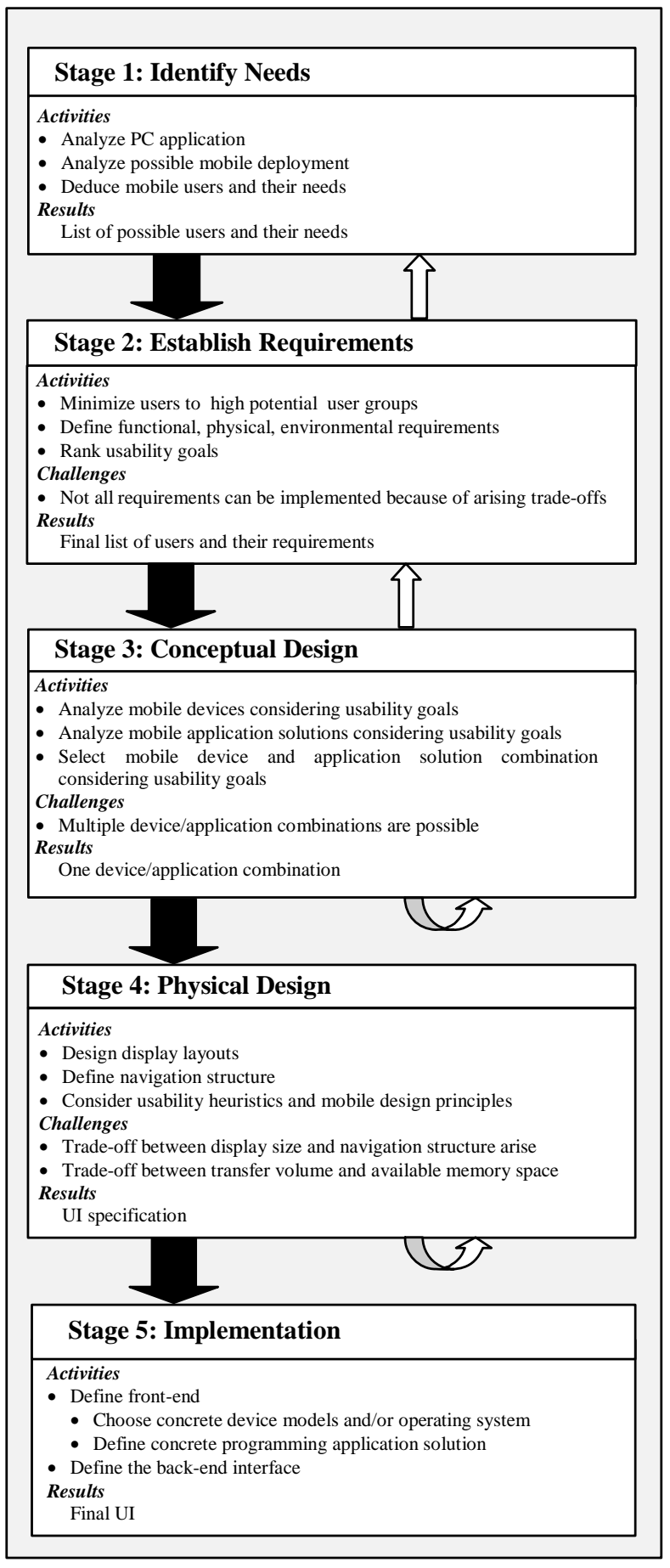

Figure 1: Overview of the M-Business Procedure Model 
Several SDLC models, including the classical software life cycle model or the spiral model, recommend an iterative software development process ([13], p. 98). However, in our model we advise against such a procedure. Repeating the design process after the first cycle, may often result in a functional overloaded UI, unreasonable large user groups as well as decreased usability. Mobile UIs are very limited. Therefore, continuously enhancing the UI, which is common in ebusiness application design, is not practical in $\mathrm{m}$ business. In particular, if the user group or the number of device types (cell phone, PDA, etc.) is planned to be extended, caution is advised. For a completely different user group with a changed application context, an additional new m-business UI, created in a new process instance, will better accomplish usability. However, sometimes after deployment, functionality turns out to be dispensable. In this case, the design process should be repeated to reduce functionality and decrease the UI's complexity.

In dependence on general user-centered design processes and specific mobile design principles, the $\mathrm{m}$ business procedure model pursues a strong focus on the user. Thus, as will be seen in the following section, usability goals are predominant throughout the entire design process.

\subsection{Stages of the Model}

In the following, the five stages of the model are explained (see figure 1 ).

Stage 1, Identify Needs: First, to identify the needs of a new mobile user interface the existing applications have to be analyzed. One of mobile applications' characteristics is the personalization and customization in regard to the user and context [25]. Therefore, the current users must be identified and examined. The tasks, which these users accomplish with the system and the functionality, which is relevant for these tasks, must be defined ([18], pp. 51-90). Afterwards, in the same way the application's possible mobile deployment must be determined.

For a mobile UI it is important that it is kept small and simple ([24], pp. 34-42). Hence, the mobile UI must only provide information and functionality that is needed in mobile processes ([26], [24]; pp. 343-346; [27], pp. 23-24). To filter out the expedient functionality, task-technology fit methods can be applied ([28]; [29]; [30]).Using these methods for the selection of users, exclusively the users, which will profit from a mobile UI, the mobile tasks and the needed functionality, will remain.

After decreasing the number of possible users, their characteristics and needs must be determined. Decisive criteria are general human characteristics such as job functionality, computer literacy and age. Additionally, application specific characteristics including users' tasks (kind of task, frequency, site, duration time or demand for real-time solution) are important ([18], pp. 51-126; [31]).

Stage 2, Establish Requirements: In the next development stage, based on the users' needs, their requirements are interpreted ([32], pp. 90-96). Requirements include context of use, data requirements, functional requirements and usability requirements ([22], pp. 204209).

However, in many cases, it is not reasonable to address the requirements for all possible users, which were defined in the previous stage. Attempting to meet all users' needs in one mobile UI, raises the complexity of the UI and imperils its usability. Therefore, it is essential to further minimize the number of users. Examining, which user groups will avail mostly from the m-business application, helps to prioritize the users. For the further design, the focus should be laid on the highly prioritized user groups with similar needs.

On the basis of these user groups, the requirements listed above have to be determined. To manage tradeoffs in the further development process, it is important to rank the requirements. Hence, in case of an emerging trade-off, the higher ranked requirements will be chosen. In particular, the ranking of usability goals is crucial for further design decisions. Good usability will result in high user acceptance ([33]; [34]).

Stage 3, Conceptual Design: When designing a mobile application the conceptual design stage comprises more than the regular design activities. Available devices as well as potential application solutions have to be analyzed and checked regarding the defined usability goals. Afterwards, possible combinations of both are analyzed.

In recent years, an immense development in mobile technology has occurred ([9]; [35], pp. 37-58). The mobile landscape is changing rapidly and the variety of mobile devices is becoming increasingly complex [36]; [37]. Mobile devices can be categorized into cell phone, pager, PDA and smart phone ([38], pp. 21-56; [39], pp. 61-71).

In addition to the device selection, the designer must decide between various application solutions. Application solutions cover a spectrum from no client deployment to software, which is deployed on the client. The spectrum includes voice clients, text messaging clients, wireless Internet clients, wireless Internet clients with messaging, smart clients and smart clients with messaging. With increasing capability of the client, the design process gains in complexity ([40], pp. 93-111). 
When combining device types and application solutions it becomes obvious that one single ideal solution rarely exist. Various usability trade-offs arise ([27], pp. 22-27). One example is the voice client execution on an analogue phone for the entry of high data volume. This UI is effective since it can be used everywhere. But it is also inefficient since a voice interface is not eligible as data collection UI. The described example clearly shows that simply striving for the fulfillment of all usability goals does not automatically lead to one solution, conflicting goals exist. Therefore, the importance and relevance of the different usability goals for a specific device type and application context solution should be taken into consideration. The highest ranked usability goals should be decisive for the selection.

Stage 4, Physical Design: In this phase the UI's physical appearance and application flow will be created. Similar to the previous phases the usability goals are the main focus in this phase. The selected combination of device and application solution provides a good basis for the fulfillment of the desired usability goals. However, the final fulfillment of the usability goals can only be reached in the physical design stage. For example, the combination of a smart phone and a smart client provides good possibilities to reach the usability goal efficiency. Nevertheless with an inefficient application flow this goal will be jeopardized. When designing the mobile UI in this stage, the designer must be aware of mobile characteristics including small screen size, limited bandwidth, small memory, difficult to use input techniques etc. It is decisive to apply general usability characteristics and mobile design principles [4]. Hence, for example a flat navigation structure, concise screen layouts, the use of input validation and the provision of input choices will facilitate the utilization of the UI.

Stage 5, Implementation: In this stage, the following design decisions must be made. First of all, the designer should choose a small number of concrete device models. If the device type is the PDA or the smart phone, an operating system (OS) has to be selected. It is possible to design a UI for multiple device models, but to reach a higher usability it is better to concentrate on a small range. Reason for this is that the devices may be slightly different e.g. in their screen size, resulting in unequal screen outputs and sensations for the user. Focussing on only a few devices allows tailoring the UI and its usability for each device model. The selection of one OS is founded with the variant fundamental design depending on the OS.

In a next step, a concrete programming solution has to be determined. For example, for a PDA the designer might choose from J2ME, C or C++ ([40], p. 196). A further decision that - if required - must be made for
PDAs and smart phones is the mobile database type. Here, proprietary databases, commercial relational databases, and custom-coded databases are available choices ([40], pp. 190-220).

Finally, when identifying the detailed programming structure and operational sequence, the designer should keep in mind to design for fast transaction and response times, small transfer volumes and a small size of the application including fixed application and business data.

\section{Evaluation of the Model}

Following the guidelines of Design Science we evaluated the utility, quality and efficacy of our model. Because of the model's innovative character, we chose a case study as observational evaluation method [11].

The m-business procedure model was applied in a project of the mobilization of a business process management (BPM) system. The system was already deployable in a wide range of B2B- and B2C-business processes in order to manage users' task flow. However, the Florida based US software development company planned to build a mobile UI in addition to its existing Web-UI. With this auxiliary UI the number of possible users and context of use should be extended to m-business users and mobile environments. One example for the expanded system support was recognizable in a business process to execute an insured event at an insurance company. After the introduction of the mobile UI not only employees in the office but also field sales force could benefit from the system's support. The project was completed in January 2004 after a development period of 6 months.

The project was chosen for the evaluation of the model because of its complexity. In particular, the large number of possible mobile users, the variant functionalities and m-business processes, which seemed to be applicable for the UI, accentuated typical challenges in m-business design. Therefore, the project was extremely eligible for the evaluation of how well the model deals with typical challenges of m-business design.

For the evaluation of the model the project strictly followed the guidelines given in the model. After each stage, the conducted activities, results and evolving challenges were compared to the specifications in the model. In addition, the stages' duration time, number of cycles of each stage and the project members' opinions of the model were acquired and analyzed. The model was appraised according to the above mentioned three criteria of design science: 
Utility: Analyzing the conducted project, the defined utility requirements for the model were met. The model supported the course of action. On the basis of activities and methods for each stage, the model gave auxiliary guidelines. The uncertainty and lack of knowledge in the project could be minimized. The duration time, success of the project and acceptability of the UI were according to expectations.

Quality: The formal requirements made in section 3.1 are fulfilled by the developed model. However, in the case study it became obvious that the level of detail should be improved. For example, questions regarding the exact design of a cell phone display would increase the quality of the model. With a smaller level of detail, the gathering of detailed design principles from other mobile literature would become needless. The model could give the complete information required in the development process.

Efficacy: The efficacy of the model was noticeable. Nevertheless, the determination of the exact level of efficacy was difficult. For a detailed determination of efficacy, it would be necessary to define detailed classification numbers (e.g. for the number of wrong decisions or user-acceptability). In addition, similar mbusiness projects should be conducted. In order to compare the model's precise impact on the development process, some projects should be conducted with and some without the guidance of the model. Finally, the classification numbers had to be compared to each other. However, different m-business projects are never completely equal, and therefore, the comparison of the projects would be difficult.

\section{Conclusions \& Further Research}

In this paper we proposed an m-business procedure model for the development of mobile user interfaces. For this, based on the business needs, the requirements of the model were identified. Following, we determined the major characteristics of the model. The model is composed of 5 sequential stages. For each stage, information about its activities, challenges and results is given. The model emphasizes a user-centered design taking into consideration mobile design issues. Aim of the model is to support and facilitate the management of m-business projects as well as the usability improvement of the mobile UI. For the evaluation, a case study of an m-business project, which was based on the model's specifications, was conducted and analyzed. Subsequent to the description of the model, the results of the evaluation were presented.

As described in the evaluation, the model contributes to the success of an m-business project. However, the evaluation of the model's quality also showed that the model can be further improved. A greater level of detail would enrich the model towards more concrete guidelines. Hence, the complexity of m-business projects could be further reduced.

In addition to the limitation of the detail level, the model's limitation of focusing only on the user interface must be mentioned. When adding a mobile UI to an existing application, besides the development of the mobile UI, the interface on server side must be considered. Thus, an m-business procedure model for the entire application would include the UI and the interface on the server.

Given the described limitations, the accomplishment of a model, which ideally supports the development process of the entire application, requires further research. First, the level of detail must be improved; second, the model must be extended to the support of the entire application.

\section{References}

[1] Tarasewich, P., "Designing Mobile Commerce Applications", Communications of the ACM, Vol. 46, No. 12, 2003, pp. 57-60.

[2] Urbaczewski, A., Valacich, J. S. and Jessup, L. M., "Mobile Commerce - Opportunities and Challenges", Communications of the ACM, Vol. 46, No. 12, 2003, pp. 31-32.

[3] Venkatesh, V., Ramesh, V. and Massey, A. P., "Understanding Usability in Mobile Commerce", Communications of the ACM, Vol. 46, No. 12, 2003, pp. 53-56.

[4] Benbasat, I. and Lee, Y. E., "A Framework for the Study of Customer Interface", International Journal of Electronic Commerce, Vol. 8, No. 3, 2004, pp. 79-102. [5] Lee, Y. E. and Benbasat, I., "Interface design for mobile commerce", Communications of the ACM, Vol. 46, No. 12, 2003, pp. 49-42.

[6] MacKenzie, S. and Soukoreff, W., "Text Entry for Mobile Computing: Models and Method, Theory and Practice", Human-Computer Interaction, Vol. 17, No. 2/3, 2002, pp. 147-198.

[7] Siewiorek, D. P., "New Frontiers of Application Design", Communications of the ACM, Vol. 45, No. 12, 2002, pp. 79-82.

[8] Dourish, P., "What we talk about when we talk about context", Personal and Ubiquituous Computing, Vol. 8, No. 1, 2004, pp. 19-30.

[9] Tetard, F., Patokorpi, E. and Kadyte, V., "UserCentred Design of Mobile Services for Tourists", Mobile Information Systems, pp. 155-168. 
[10] Allen, D. and Wilson, T. D., "Action, interaction and the role of ambiguity in the introduction of mobile information systems in a UK police force", Mobile Information Systems, pp. 15-36.

[11] Hevner, A. R., March, S. T., Park, J. and Ram, S., "Design Science in Information Systems Research", MIS Quarterly, Vol. 28, No. 1, 2004, pp. 75-105.

[12] Schach, S. R. (Ed.) Classical and Object-Oriented Software Engineering, McGraw-Hill Sci-

ence/Engineering/Math, Chicago, 1996.

[13] Balzert, H., Lehrbuch der Software-Technik, Band 2 - SW-Management, -Qualitätssicherung, Unternehmensmodellierung, Spektrum, Heidelberg, Berlin, 1998.

[14] Hansen, H. R. and Neumann, G. (Eds.), Wirtschaftsinformatik I, Lucius \& Lucius Verlagsgesellschaft mbH, Stuttgart, 2002.

[15] Olson, G. M. and Olson, J. S. O., "HumanComputer Interaction: Psychological Aspects of the Human Use of Computing", Annual Review of Psychology, Vol. 54, No. 1, 2003, pp. 491-516.

[16] Raskin, J., The Humane Interface - New Directions for Designing Interactive Systems, 1 ed., Addison-Wesley, New York, 2000.

[17] Nielsen, J., Usability Engineering, 1st ed., Morgan Kaufmann, San Francisco, 1994.

[18] Hackos, J. T. and Redish, J. C., User and Task Analysis for Interface Design, John Wiley \& Sons, New York, 1998.

[19] Shneiderman, B., Designing the User Interface Strategies for Effective Human-Computer Interaction, 3rd ed., Addison-Wesley, New York, 1997.

[20] Krug, S., Don't Make Me Think - A Common Sense Approach to Web Usability, 1st ed., New Riders, Indianapolis, 2000.

[21] Preece, J., Rogers, Y. and Sharp, H., Interaction Design - Beyond Human-Computer Interaction, John Wiley \& Sons, New York, 2002.

[22] Preece, J., Rogers, Y. and Sharp, H., Interaction Design - Beyond Human-Computer Interaction, John Wiley \& Sons, New York, 2002.

[23] Trump, User centred design process: ISO 12407, http://www.usability.serco.com/trump/resources/13407 stds.htm, 21.02.2005.

[24] Settles, C., Wireless Inc, American Management Association, New York, 2002.

[25] Chan, S. S., Lam, J., Fang, X. and Brzezinski, J., "Customization and Customer Satisfaction for Mobile Commerce", Proceedings of the Tenth Americas Conference in Information Systems 2004, pp. 3877-3884. [26] Sun, J., "Information requirement elicitation in mobile commerce", Communications of the ACM, Vol. 46, No. 12, 2003, pp. 45-47.
[27] Sadeh, N., M Commerce: Technologies, Services, and Business Models, John Wiley \& Sons, New York, 2002.

[28] Gebauer, J., Shaw, M. J. and Gribbins, M. L., "Usage and Impact of Mobile Business Applications An Assessment Based on the Concepts of Task/Technology Fit", Proceedings of the Tenth Americas Conference on Information Systems, pp. 2801-2810.

[29] Lee, K. C., Lee, S. and Kim, J. S., "Analysis of Mobile Commerce Performance by using the TaskTechnology Fit", Mobile Information Systems, pp. 135154.

[30] Dishaw, M. T., Strong, D. M. and Bandy, D. B., "The Impact of Task-Technology Fit in Technology Acceptance and Utilization Models", Proceedings of the Tenth Americas Conference on Information Systems, pp. 3306-3311.

[31] Davis, G. B., "Anytime/Anyplace Computing and the Future of Knowledge Work", Communications of the ACM, Vol. 45, No. 12, 2004,

[32] Deutsch, M. S. and Willis, R. R., Software Quality Engineering - A Total Technical and Management Approach, Prentice Hall, Englewood Cliffs, 1988. [33] Seffah, A. and Metzger, E., "The Obstacles and Myths of Usability and Software Engineering", Communications of the ACM, Vol. 47, No. 12, 2004, pp. 71-76.

[34] Venkatesh, V., Morris, M. G., Davis, G. B. and Davis, F. D., "User Acceptance of Information Technology: Toward A Unified View", MIS Quarterly, Vol. 27, No. 3, 2003, pp. 425-478.

[35] Funk, J. L., Mobile Disruption: The Technologies and Applications Driving the Mobile Internet, Jon Wiley \& Sons, Hoboken, 2003.

[36] BenMoussa, C., "A Task-Based Framework of Styles for Mobile Applications to Enhance Salespersons' Performance", Mobile Information Systems, pp. 51-64.

[37] Banavar, G. and Bernstein, A., "Software Infrastructure and Design Challenges for Ubiquitous Computing Application", Communications of the ACM, Vol. 45, No. 12, 2002, pp. 92-96.

[38] Weiss, S., Handheld Usability, 1st ed., John Wiley \& Sons, 2002.

[39] Turowski, K. and Pousttchi, K., Mobile Commerce: Grundlagen und Techniken, Springer, Berlin, 2003. [40] Mallick, M., Mobile and Wireless Design Essentials, 1 ed., John Wiley \& Sons, Indianapolis, 2003. 